\title{
Editorial
}

\section{Scientific Primacy in Implantology}

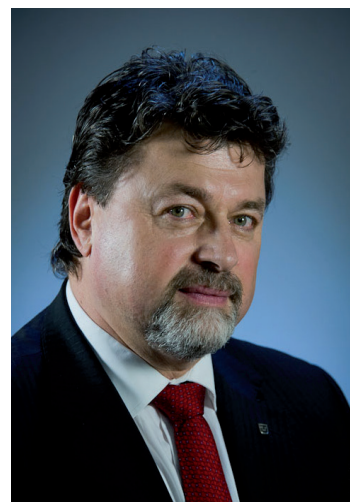

\author{
Dr.h.c. prof. Ing. Jozef Živč́k, PhD., MPH \\ Head of the Institute of Special Engineering Processologies
}

There are profiled within this Institute the interdisciplinary study branches as follows: the Biomedical Engineering, the Measuring, the Quality and Safety of Technical Systems.

The main professional domain of Mr. prof. Živčák is the area of biomedical engineering, namely in the profile of implantology. The biomedical engineering belongs among the interdisciplinary professional branches where it is presenting its scientific platform through a development, research and implementation of new and non-conventional materials specified for application in the implantology, which is relating to the whole human body skeleton. Other scientific priorities in the implantology are the tailor-made implants, for example:

\section{- Implant of jowl after tumour affection, \\ - Implants of intervertebral discs after a degenerative affection, \\ - Pectoral implant after oncologic affection, \\ - Implant for schizoprosopia of a newborn child.}

The above-mentioned implants are the European and worldwide successes achieved during the last year. These implants were realised for the Slovak patients at the Department of Biomedical Engineering and Measuring, Faculty of Mechanical Engineering, Technical University of Košice. This Department is cooperating with many home and foreign universities, university hospitals and industrial companies, for example with the domestic universities: UPJŠ-Košice, UVLaF-Košice, UK-Bratislava, PU-Prešov, ZA-Žilina, STU-Bratislava; with the foreign universities: University Aachen Germany, ČVUT-Prague, VUT-Brno, PT-Bialystok, Poland, UCH-Illinois, USA, University Gent, Belgium, University Nice, France; with the university hospital UN-Martin and with the companies: Biomedical Engineering Ltd. Košice, EOS, Germany, ZEISS, Germany etc.

The departmental research is organised in an original way within this Department, because it is developed on a common platform, which is based on the departmental employees, departmental students, production companies and scientific institutions. The trendiest research intentions are presented by means of the extensive research project activities performed by the departmental scientific teams, which are involved in the various home and foreign grant projects.

Implementation of the students into the scientific-research cooperation activities creates a synergic effect, which is presented in a form of the so-called database of the explicit professionals who are acting in the area of implantology and who are large-spectrally educated in the study branches of machine design, engineering technologies, technical materials and application of a paradigm. 


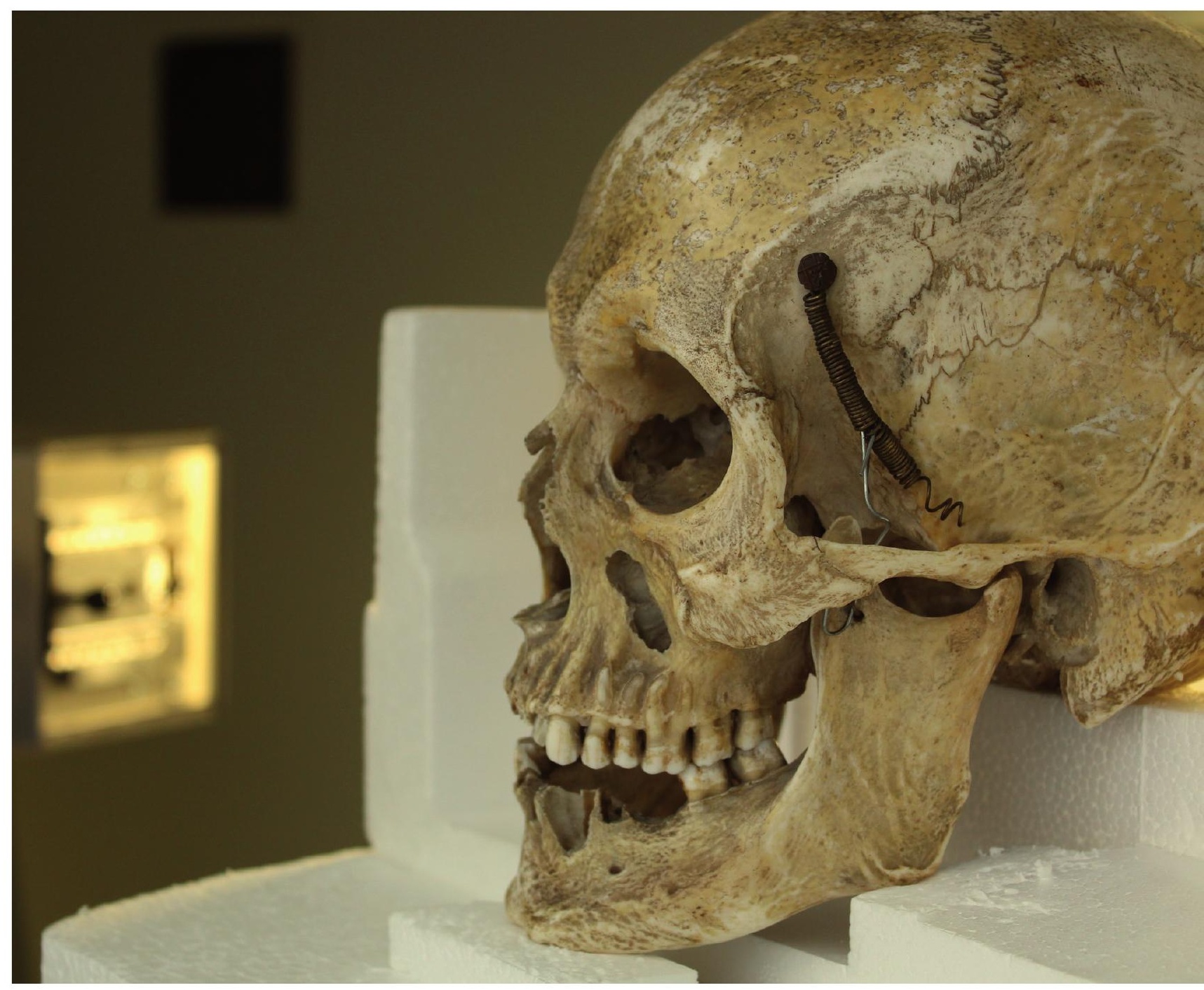

An added valued of the research in implantology is a $100 \%$ application of the results in the practice, whereby all the demanding research activities are directly transformed into the practical utilization within a real time and bringing the so-called return effect, as well.

The successes reached thanks to effort of the departmental working team are appreciated not only by the satisfied patients, i.e. in a way of moral appreciation, but they are also officially awarded in the form of various acknowledgements obtained from the Ministry of Education, for example:

\section{- the technologist of the year,} - the scientist of the year,

as well as in the form of various medial presentations focused on the other results achieved at the
Department of Biomedical Engineering and Measuring under the direction of prof. Živčák.

A feedback of the research results and successes is also presented by the steadily new and new requirements coming from the patients. These positive facts offer new opportunities for the next innovations created in the area of implant architecture as well as for application of the new materials, such as the PEEK, glass metals, ceramic implants or magnesia materials.

A valuable satisfaction for the biomedical engineering area represents a permanent interest of the students who are registered for this branch of study within the Faculty of Mechanical Engineering at the Technical University of Košice. 